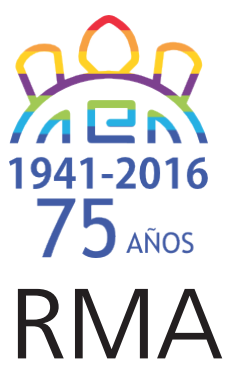

Dossier

\title{
Procesos comunes y trayectorias diferentes en torno a las tierras de los pueblos de indios de Jujuy. Siglo XVI al XIX
}

\author{
Common processes and different trayectories around the \\ lands of indians villages of Jujuy. Between the XVII and XIX \\ centuries
}

Gabriela Sica*

*CONICET, ISHIR-Unidad de Investigación en Historia Regional, Facultad de Humanidades y Ciencias Sociales, Universidad Nacional de Jujuy. E-mail: gabrielasica@gmail.com

\begin{abstract}
Resumen
Este trabajo analiza la historia de los pueblos de indios de Jujuy y sus tierras comunales desde la pacificación definitiva de su territorio a fines del siglo XVI hasta las primeras décadas del siglo XIX. En esta historia de larga duración hay algunos procesos comunes y diferencias regionales condicionadas por su ubicación, peso demográfico, acceso a recursos y relación con los encomenderos. En los procesos comunes se destacan la capacidad política de las autoridades étnicas para negociar, recurrir a la justicia o al amparo de las autoridades en las coyunturas militares o políticas que podían ser favorables. La declinación y extinción de varios de estos pueblos se producirá en las últimas décadas del siglo XVIII y las primeras décadas del siglo XIX por el avance de la propiedad privada y las nuevas ideas liberales.
\end{abstract}

Palabras clave: pueblo de indios; tierras comunales; Jujuy; Colonia.

\begin{abstract}
This paper analyzes the history of the Indian villages of Jujuy and their communal lands from the final pacification of its territory in the late sixteenth century to the early decades of the nineteenth century. In this long history there are some common processes and regional differences conditioned by location, demography, access to resources and relationships with the "encomenderos". They highlight the political capacity of ethnic authorities to negotiate in common processes, recourse to justice or under the authorities in military or political situations that could be favorable. The decline and extinction of several of these "pueblos de indios" will occur in the last decades of the eighteenth century and the first decades of the nineteenth century by the advance of private property and the new liberal ideas.
\end{abstract}

Keywords: Indian villages; Community lands; Jujuy; Colony.

En 1839 la legislatura de la nueva provincia de Jujuy discutía el proyecto por el cual extensas tierras agrícolas y de pastoreo pertenecientes a las comunidades indígenas coloniales debían transformarse y reconvertirse bajo los nuevos principios liberales. Sin embargo, a pesar que en la etapa colonial la jurisdicción de Jujuy era una de las regiones, de la gobernación de Tucumán, en donde los pueblos de indios ${ }^{1}$ tuvieron una larga pervivencia y estabilidad, las preocupaciones de los legisladores sólo estaban centradas en la Quebrada de Humahuaca. En ese momento solamente en esta región existían tierras comunales y las razones de su perduración y de la desaparición de otros pueblos de indios de la jurisdicción

\footnotetext{
${ }^{1}$ Como sostiene Castro Olañeta, consideramos al pueblo de indios en la Gobernación de Tucumán como una unidad social, tributaria y territorial que suponía la existencia de tres características distintivas el usufructo en común de la tierra; un conjunto de autoridades propias y la carga tributaria para quienes revestían la condición de originarios (Castro Olañeta 2006: 40).
}

era resultado de una larga y compleja historia, con elementos comunes y algunas trayectorias diferenciadas.

El objetivo central de este trabajo es analizar, en larga duración, la relación de los pueblos de indios y sus tierras comunales en la jurisdicción de San Salvador de Jujuy desde la concesión de las primeras encomiendas en el siglo XVI hasta las primeras décadas del XIX.

Nuestra hipótesis es que la creación y consolidación de los pueblos de indios de Jujuy fue un proceso relativamente temprano que se desarrolló desde las últimas décadas del siglo XVI. En él se pusieron en juego los intereses de los encomenderos, la capacidad política de las autoridades indígenas, las coyunturas económicas y la ubicación de los mismos en relación a circuitos y mercados. La adquisición y mantenimientos de sus tierras tuvo diferencias regionales y estuvo marcada por distintas coyunturas militares y políticas: la primera se abrió con

Recibido 03-08-2016. Recibido con correcciones 31-10-2016. Aceptado 01-11-2016. 
la pacificación definitiva del territorio y se cerró con la visita de Alfaro. Una segunda estuvo dada por la creación de una frontera de guerra con los grupos chaqueños y el contexto favorable creado por las medidas y gestiones de algunos gobernadores en el marco de las políticas posalfarianas y de la guerra en los valles Calchaqui. Los procesos de disolución o continuidad de pueblo y tierras en el siglo XVIII estuvieron condicionados por las coyunturas brindadas por la incorporación de nuevos territorios por los avances sobre la frontera oriental y la finalización de algunas encomiendas.

La historia de los pueblos de indios de Jujuy y la relación con sus tierras en el extenso lapso que abarca desde su creación hasta su disolución, sólo puede ser reconstruida a partir de los diferentes avances de nuestra propia investigación y de otros colegas, como Zanolli, Sánchez, Castro Olañeta y especialmente Palomeque a los que hay que sumar los aportes pioneros de Madrazo; y de una amplia búsqueda de diversas fuentes (mercedes, juicios, cartas de venta, testamentos, informes de autoridades, padrones, etc.) que dan cuenta de algunos procesos comunes y de sus trayectorias divergentes.

\section{Dominando el territorio, "sujetando" la población. El proceso de concesión de las encomiendas en la jurisdicción de San Salvador de Jujuy a fines del siglo XVI}

La conquista del territorio y la concesión de las encomiendas que dan lugar a la creación de los pueblos de indios en la jurisdicción de Jujuy fue un largo proceso vinculado al avance de las huestes desde Charcas, y las fundaciones de Tarija y luego de Salta. En el caso de las tierras altas, Francisco Pizarro, entre 1539 y 1540, asignó las primeras encomiendas para el Perú y en ellas se incluyeron poblaciones que vivían en la futura jurisdicción de Jujuy (Zanolli 2005). También en Salta en tanto se otorgaron pueblos en la Puna, la Quebrada, el valle de Jujuy y los valles calchaquíes (a Monje, Villanueva, Barba y Castillo) las cuales sólo sirvieron para que sus encomenderos participaran infructuosamente en su conquista, perdiendo su vida muchas veces (Palomeque 2006). Estos primeros beneficiarios -Martín Monje y Juan de Villanueva- poseían fuertes intereses, así como, redes económicas y parentales vinculadas con Charcas, la ciudad de La Plata y Tarija. De ellas, se derivaron las encomiendas de Omaguaca y Casabindo y Cochinoca (Zanolli 2005; Palomeque 2006) ubicadas en las tierras altas de Puna, donde se practicaba generalmente la ganadería sobre todo en su sector norte, mientras hacia el sur iban siendo cada vez más áridas hasta llegar a las salinas (Albeck 1992, Albeck y Palomeque 2006).

Hacia el oriente, diversos valles y relieves permitían la bajada desde las tierras de la Puna y la Quebrada hacia las tierras bajas. Esta es la zona de la frontera inca pronto desestructurada, donde se asentaban grupos, algunos de ellos incluidos en las encomiendas más tempranas de
Humahuaca y la Puna y que algunos estudios identificaron como mitimaes incaicos (Lorandi 1984, Sánchez y Sica 1990, Ventura 2001, Oliveto y Ventura 2009, Ventura y Oliveto 2014).

De estos valles, al Norte encontramos a los de Nazareno e Iruya, ubicados al Este de las Serranías de Zenta y Santa Victoria, mientras que, al Oriente de Humahuaca, el valle continúa por otro río hacia Coctaca, interrumpida por las altas cumbres del Zenta que, a su vez, hacia el Oriente se abren en un conjunto de ríos y montañas que a medida que desciende la altitud se vuelven más cálidas y que suelen denominarse las yungas.

Recién cuatro décadas después de las primeras mercedes y antes de la fundación definitiva de la ciudad de Jujuy, entre 1583 y 1584, el gobernador Lerma otorgó las encomiendas de Tilián, Purmamarca, Ocloya, Churumatas, Yala y Paipaya a vecinos de la ciudad de Salta (Doucet 1993, Sica 1992 y 2006). En 1593, Francisco de Argañaraz en su carácter de fundador de Jujuy, se concedió a sí mismo la última encomienda. Esta merced fue la de: Tilcara, Ossas y Gaypetes (Sánchez 1996). Es decir que a lo largo de 40 años logran adjudicarse encomiendas primero en la Puna y en el sector norte de la Quebrada de Humahuaca y por último en el centro y sur de la Quebrada y el norte de la frontera oriental.

En la jurisdicción de Jujuy, el poder colonial quedó consolidado más tempranamente en relación a otras regiones de la gobernación de Tucumán, y casi todas sus encomiendas se fueron efectivizando desde finales del siglo XVI, cuando la fundación de la nueva ciudad delimito la jurisdicción de la ciudad y los nuevos encomenderos comenzaron un proceso de traslado de pueblos desde la frontera oriental incaica hacia la zona colonial controlada cercana al valle de Jujuy, ubicada al suroeste de la antigua frontera incaica que venía siendo destruida por el avance de los grupos selváticos.

Como era la práctica común en la gobernación, los propios encomenderos fueron los encargados de reducir a la población. La mayor parte de estas fundaciones se realizaron entre 1593 y 1630. En este lapso culminaron muchos de los conflictos por las encomiendas, se instalaron en la ciudad sus poseedores y se pusieron en marcha distintas actividades productivas, para las cuales era importante disponer de mano de obra.

En las concentraciones y agregación de la población indígena de Jujuy en pueblos de indios se dieron diferentes situaciones que iban desde las poblaciones que fueron desnaturalizadas y asentadas fuera de la jurisdicción hasta las que se reagruparon en territorios cercanos a sus antiguos sitios prehispánicos. Aunque, esta parecía la opción menos traumática hay que recordar que la concesión en encomiendas y la concentración de su población en reducciones alteraba profundamente la antigua territorialidad, el acceso a recursos, fragmentaba 
muchas veces a grupos más amplios y transformaba la relación simbólica con el espacio y el paisaje. En la historia de la creación de los pueblos de indios hubo marcadas diferencias en cuanto al modo y la época en que esto se realizó, ellas estuvieron condicionadas por su ubicación geográfica y ecológica, la disponibilidad de recursos y la relación con las nuevas propiedades que conllevaba la ocupación europea.

Dentro de la quebrada de Humahuaca, la fundación de Jujuy y la campaña militar de Argañaraz en 1595 permitió a los españoles la ocupación definitiva de parte del territorio antes controlado por el Tawantinsuyo, la creación de las primeras reducciones y la concesión de las primeras mercedes de tierras a los conquistadores.

A comienzos de 1595, según Lozano, el jesuita Gaspar Monroy entró a la Quebrada y se reunió con el líder de la resistencia contra la ocupación española llamado Viltipoco. El sacerdote habría actuado como mediador para lograr la pacificación de la zona (Lozano 1874:411). Vergara, basándose en la historia del padre Guevara, nos brinda mayores especificaciones sobre este encuentro. En él, Viltipoco y los señores de Omaguaca habrían capitulado y pactado algunas condiciones con el padre Monroy quien actuaba en nombre del gobernador de Tucumán Don Fernando de Zárate² (Vergara 1961:39). Hay que recordar que Viltipoco poseía experiencia en los procesos de negociación con las autoridades europeas buscando las mejores ventajas ante la inminencia de la ocupación militar y una posible derrota; unos años antes había intentado llegar a un acuerdo con la Audiencia de Charcas para que los encomenderos de Charcas no entraran al territorio a cambio de rehabilitar los antiguos tambos incaicos para la circulación mercantil (Palomeque 2006). Los rumores de una nueva sublevación indígena habrían acabado bruscamente con los avances logrados por los jesuitas y desencadenado una ofensiva militar enviada por el nuevo gobernador de Tucumán y liderada por el fundador de Jujuy Argañaraz. En esta entrada fueron capturado Viltipoco y cuatro caciques principales de la Quebrada (ATJ legajo 23, 1596: 2.v.). Este hecho no sólo permitió las tomas de posesión de las encomiendas de la Quebrada sino también el comienzo del traslado de la población encomendada que vivía en la frontera oriental logrado a partir de la intermediación y negociación de los caciques quebradeños (ATJ legajo 23, 1596; ATJ legajo 4, 1595). Según algunos testimonios contemporáneos, Viltipoco habría logrado que los caciques Ossa y Paipaya se rindieran, mientras que los principales de Humahuaca lo habrían hecho con grupos del Valle de Ocloya (ATJ legajo 4, 1595). También, Viltipoco habría mediado ente el cacique Laysa de Churumatas para que este abandonara sus tierras y se reubicara con su gente en el valle, pero ante su negativa el gobernador Mercado Peñaloza ordenó a Argañaraz realizar una nueva entrada punitiva que terminó con su captura y su traslado hacía

\footnotetext{
${ }^{2}$ Fernando de Zárate fue Gobernador de Tucumán desde abril de 1593 hasta julio de 1595.
}

la ciudad, donde fue entregado a su encomendero (ATJ legajo 23, 1595: 2v.). El reasentamiento de la población de los valles orientales en zonas más accesibles a los españoles era vital, para la nueva ciudad de Jujuy, no sólo para asegurar que se avecindaran sus encomenderos que vivían en Salta, sino también para terminar de revalidar la jurisdicción de la ciudad de Jujuy frente a la de Salta ${ }^{3}$ y sobre todo neutralizar el peligro de posibles alianzas de estos grupos con los chiriguanos que presionaban sobre esta porción de la frontera 4 .

\section{Tierras y pueblos de indios en las tierras altas de la jurisdicción de Jujuy: Puna y Quebrada de Humahuaca. Entre propiedad y usufructo}

En el caso de las tierras altas de Jujuy, la fundación de la ciudad de San Salvador de Jujuy y las campañas militares sobre el territorio permitieron las tomas de posesión definitivas de estas encomiendas y la reducción de la población indígena en pueblos de indios. También se consolidó el paso permanente del camino real por la quebrada de Humahuaca y se otorgaron las primeras mercedes de tierra a españoles en la zona. En ellas, aparecen menciones sobre tierras indígenas como linderos dando cuenta, indirectamente, de su existencia. Por ejemplo, cuando Francisco de Argañaraz, teniente de gobernador de Jujuy, le otorgó la merced de la estancia de Omaguaca en noviembre de 1595, la misma tenía como límite sur: "las tierras de los indios de omaguaca" (Zanolli 2005:129).

En la ocupación española de la quebrada de Humahuaca, este reconocimiento temprano de tierras de propiedad indígena también condicionó la entrega de las nuevas mercedes. Las mismas se fueron estableciendo en los límites de las tierras comunales desde 1595 (Sica 2014a).

\footnotetext{
${ }^{3}$ Esto se puede ver en los memoriales y pedidos que los procuradores y el cabildo de Jujuy elevaron a los gobernadores de Tucumán entre 1595 y 1606. En algunas partes de ellas pedían reiteradamente: " pido y suplico al ... sea serbido de mandar que todos los que tienen en esta ciudad solares estancias y chacras acudan a poblarla y asi mesmo se les de mandamiento al gobernador y vecinos de Salta que los tienen que bengan aquí a poblarlas y abencindarla como son el capitan Juan Rodriguez $\}$ encomendero de churumatas] y Alonso de Tobar Jencomendero de Yala] y otros los quales tienen en esta ciudad solares chacaras y estancias les mande Vuessa merced bengan personamelmente a abençindarse a esta ciudad...". (Pedido del procurador de la ciudad de Jujuy al gobernador Mercado de Peñaloza. ATJ legajo 23, 1596: 3-3v.) "...y ten pedir a su señoria que los yndios que estaba de esa otra parte del rio de xujuy azia Tarija chiriguanaes y frentones $y$ otros de otra nacion que sean rio arriba y rio abaxo se le de a esta ciudad pues esta en esta jurisdiccion y termino della pues es ordenança Real sirban a la ciudad más zercana y es a lo es y de les estan doçe legajouas de camino y rios donde pueden cometer riego que ay de aquí a la de salta y de paipaya y ossas y Ocloya y los churumatas estan de esta ciudad diez y doçe legajouas y no es justo que esta ciudad sirba solo de frontera a la de salta..." (Pedido del cabildo de Jujuy al Gobernador Alonso de Rivera. ATJ legajo 23, 1601: 8 v.)

4 "..por aber estado en riesgo como es notorio de los yndios laysay circunvecinos chiriguanaes y otras naciones que se convocaron $y$ juntaron con animo dañino intentaron dar asalto a esta ciudad para matar a la gente en ella..." (Acta de Cabildo del 25 de octubre de 1596 ATJ legajo 3, 1596:125).
} 
Mientras que las propiedades españolas se multiplicaron en el sector S de la Quebrada. Las únicas excepciones de mercedes ubicadas en el fondo de valle en tierras que podrían corresponder a indígenas fueron las de Huacalera adjudicada por el gobernador Fernando de Zárate a Juan Ochoa de Zárate (encomendero de Humahuaca) en $1593^{5}$ y la merced de un tambo en Tilcara en 1596 (Zanolli 2005:128, Sica 2014a:24).

Los principales pueblos de indios fueron establecidos en la Puna y la quebrada de Humahuaca en los últimos años del siglo XVI y la primera década del siglo XVII. Si bien no tenemos una fecha concreta de fundación, ya que la práctica en la gobernación era el de la fundación privada de los encomenderos con escasa injerencia estatal.

Lo cierto es que a principio de 1600 ya existían los pueblos de San Antonio de Humahuaca ${ }^{6}$ y San Francisco de Tilcara ubicados sobre el fondo de valle y sobre el camino real. Los mismos tenían tierras de su propiedad que parecen datar de finales del siglo XVI. El pueblo de Tilcara, fundado en las cercanías de un antiguo pucará prehispánico, legalizó la tenencia de un importante territorio a través de un temprano pedido de merced al Rey. La misma y las primeras tomas de posesión tuvieron lugar antes de la llegada del visitador Alfaro. En 1606, el cacique reclamaba ante el Rey la propiedad de unas tierras que: "... de tiempo tenido y poseído e poseen al presente como tierras propias y por inmemorial a esta parte an suyas..." (ATJ legajo 749, 1699: 1. El subrayado es nuestro). Estas comprendían seis leguas lineales que de $\mathrm{S}$ a $\mathrm{N}$ que recorrían el espacio que iba desde la boca de la quebrada de Purmamarca hasta el Angosto de Perchel con dos leguas de ancho a cada banda (Salas 1945, Sánchez y Sica1991, Sánchez 1996, Sica 2006 y 2014a)7. La propiedad de estas tierras fue ratificada por el teniente de gobernador de Jujuy en1606, por el gobernador de Tucumán en 1609, por el visitador Alfaro en 1612 y por la Audiencia de Charcas en 1613.

\footnotetext{
${ }^{5}$ En este caso, el gobernador Zárate entregó el título de la merced antes de que la zona estuviera pacificada.

${ }^{6}$ Estimamos que fundado a finales del siglo XVI. Para Zanolli, su fundación databa de 1595 luego que se concretara el establecimiento de San Salvador de Jujuy en abril de 1593, y sus límites jurisdiccionales (Zanolli 2005:134). Una de las primeras noticias de este pueblo se puede encontrar en la descripción de Lizárraga: "...Desde aquí [Calahoyo] al primer pueblo de españoles de la provincia de Tucumán, llamado Salta, ponen más de cien legajouas, todas despobladas, a lo menos por el camino que yo fui siendo provincial de aquella provincia y de la de Chile, que por dar orden en ciertos frailes nuestros que allí estaban me fue forzoso desde la ciudad de Lima tomar este camino por tierra. Empero al presente, después que la provincia de Omaguaca, .. se ha reducido y admitido sacerdotes..." (Lizarraga1928:225) (El subrayado es nuestro). Sabemos que la descripción de Lizárraga es producto de las experiencias de sus viajes en diferentes momentos que luego volcaba en su relato, algunos autores como Palomeque, están de acuerdo que el primer viaje por la Puna se realizó en 1589 y 1591. En otras fuentes, las primeras menciones sobre el pueblo de San Antonio de Humahuaca corresponden al año 1600 (Zanolli 2005:129, Sica 2006:204)

${ }^{7}$ La extensión de las tierras de Tilcara es conocida a partir del traslado y copia de la merced original. La misma ha sido analizada por los autores citados.
}

El más tardío en su conformación, dentro de la Quebrada de Humahuaca fue el pueblo de Santa Rosa de Purmamarca. El espacio elegido para levantarlo fue en las márgenes del río del mismo nombre. Fue uno de los últimos pueblos indios de la Quebrada, ya que recién fue fundado por su tercer encomendero, Martín de Argañaraz en la segunda mitad del siglo XVII (Sica 2006). A pesar de ello, los integrantes de esta encomienda poseían tierras antes de la fundación del pueblo colonial y previas a la llegada del visitador Alfaro. Según datos posteriores, ellas recorrían el fondo de la quebrada de Purmamarca hasta la unión de la misma con la quebrada troncal, punto en el que lindaban con las tierras del pueblo de Tilcara ${ }^{8}$. En 1612, cuando el visitador Alfaro ratificó la posesión de las tierras de comunidad de los integrantes de Tilcara, convocó al cacique de Purmamarca como vecinos a fin de que controlaran este acto. Posiblemente, en ese momento también ratificara la posesión de las tierras que ascendían por esta quebrada como tierras comunales.

En el sector S de Humahuaca, la población de esta zona fue incorporada en la encomienda de Tilián. Desde 1596, existen quejas del cabildo de Jujuy ante el gobernador sobre el traslado que el encomendero había realizado hacia la jurisdicción de Salta, en donde quedaron asentados definitivamente ${ }^{9}$. Pedro Marco vecino de la ciudad de Salta había obtenido la encomienda de Tilián en la década de 1580. En los primeros años de existencia de Jujuy y en el marco de las tensiones políticas que generó su fundación, ya que la misma cercenaba gran parte del territorio comprendido por la antigua jurisdicción de Salta (Rojas 1913:13, Vergara 1966, Palomeque 2006, Sica 2006: 95-97), Marco trasladó la población de su encomienda a la ciudad de Salta. De este modo, el encomendero de Tilián trató de evitar que su encomienda mudara de jurisdicción con los correspondientes conflictos que implicaba la situación de doble vecindad, ya que tenía otra encomienda en Salta (ATJ legajo 23,1596).

Resulta más que sugerente que los tres pueblos de indios de la Quebrada (Humahuaca, Tilcara y Purmamarca) accedieran a extensas tierras comunales casi desde el momento en que terminó la pacificación definitiva de la zona. Posesión que lograron antes de la llegada de Alfaro y que fuera respetada en el reparto de las primeras mercedes de tierras. Podemos hipotetizar la existencia de una negociación entre Viltipoco y los caciques de Humahuaca con las autoridades españolas, que tuvo como base el compromiso de conservar algunas tierras a cambio de asegurar el transito fluido por la Quebrada, las tomas de posesión definitivas de las encomiendas de la zona ${ }^{10}$, el comienzo de las primeras reducciones y el

\footnotetext{
${ }^{8}$ Las referencias sobre su ubicación han sido reconstruidas de manera aproximada a partir de los expedientes del proceso de enfiteusis AHPJ Libro 1. Año 1849 "Relativo a la enajenación y venta en enfiteusis de los terrenos de utilidad pública existentes en Tilcara y toda la comprensión de este Departamento formado de orden superior del Gobierno de la Provincia de Jujuy por su Comisionado General Manuel Rosa de la Quintana". Agradezco a Cecilia Fandos las copias de dicho documento.

9 El pueblo de Tilián aparece relacionados con las encomiendas de Pulares, reducidos en las proximidades de la ciudad de Salta perdurando hasta el Siglo XVIII (Castro Olañeta 2007: 12).

${ }^{10}$ A excepción de la encomienda de Omaguaca, cuyo encomendero vecino de Charcas había tomado posesión de ella en Cochinoca en
} 
traslado de las poblaciones de los valles orientales hacia la nueva frontera del valle de Jujuy.

En la Puna, que fue la sede de otra de las encomiendas más antiguos. Sus primeros encomenderos tomaron posesión de ellos y cobraron tributos o escasamente lograron y o exigieron servicios personales esporádicamente durante la segunda mitad del siglo XVI, pero no redujeron a su población (Zanolli 2005, Palomeque 2006 y 2015). Recién, después de la derrota militar que las huestes tucumanas infringieron al cacique Quiliquipildor y su gente en 1588/9 en Casabindo mientras estaban negociando su sujeción a Charcas, se sometieron estos pueblos y aceptaron como su encomendero a Lorenzo de Aldana, hijo de Martín Monje, quien falleció en 1602 y permitió el ingreso del encomendero Cristóbal Sanabria (vecino de Salta) (Palomeque 2006). En 1602, Sanabria el nuevo encomendero de Casabindo y Cochinoca realizó un contrato con Pedro Zamora para que administre y reduzca a los indios de su encomienda. Sanabria no hacía más que seguir el modelo tucumano de reducciones privadas (Albeck y Palomeque 2009) ${ }^{11}$.

La finalidad que perseguía Sanabria, según Palomeque, era agrupar a la población de la encomienda para poder exigir sus tributos en trabajo minero en un momento de expansión de esta actividad. En la creación de estas reducciones el más afectado por el traslado fue el pueblo de Cochinoca ya que en sus tierras habían comenzado a desarrollarse las primeras explotaciones mineras de la puna, según referencias de Albeck en Palomeque 2006). Su localización original estaba en el Pucará de la Rinconada (al SO de la cuenca de la laguna de Pozuelos) y el emplazamiento colonial fue localizado a una importante distancia de allí, al lado del camino inca. Al contrario, el pueblo de Santa Ana de Casabindo, quedo situado en un área cercana a los restos arqueológicos de su "pueblo viejo" (Albeck y Palomeque 2006, Palomeque 2006 y 2015).

En algunas mercedes de tierras de finales del siglo XVI, habría evidencia indirecta sobre tierras de los indios de Cochinoca. La merced de la estancia de Omaguaca, antes citada, tenía por lindero por "... tierras del pueblo de cochinoca..." (citado en Zanolli 2005:129). Es posible que esta posesión se perdiera con el traslado a la reducción unos años después. Una década más tarde el Oidor Alfaro, de cuyas Ordenanzas se desprende que visitó Casabindo y Cochinoca les adjudicó sus tierras de reducción para luego fijarles una tasa en especie en productos específicos de esa zona (Albeck y Palomeque 2009, Palomeque 2006 y

1593, a pocos meses de la fundación de San Salvador de Jujuy (Zanolli 2005:124)

11 En el año 1573 el segmento sur los pueblos chichas que estaban sublevados, negociaron con el visitador enviado por el virrey Toledo y aceptaron ser "reducidos" hacia Talina mientras mantenían sus derechos a las tierras de sus antiguos asentamientos ubicados al norte de la línea que va de la laguna de Pozuelos a Cangrejos (Albeck y Palomeque 2009: 186, Palomeque 2010). Uno de sus ayllus, el de Sococha, que también fue reducido en Talina, optó luego por retornar a sus antiguas tierras (Palomeque 2010), quedando así reducidos en San Rafael de Sococha (Zanolli 2005:107). El pueblo de San Rafael de Sococha, fuera de la jurisdicción de la gobernación de Tucumán, formó parte de la encomienda de Omaguaca hasta 1735 cuando fue separada por el gobernador (AGI, Charcas 259-1:34 v.) Agradezco a Sonia Tell la copia de este documento.
2015). Sin embargo, el proceso de pérdida de estas tierras se acentúo con la llegada de Pablo Bernárdez de Ovando a la encomienda.

En 1655, el nuevo encomendero solicitó una merced de tierras sobre la Quebrada de las Leñas, según Albeck y Palomeque, esta era una importante extensión de tierra que comprendía las antiguas concesiones de Quera y de Echira. Las mismas estaban ocupadas por los pueblos de Casabindo y Cochinoca, con excepción de la parte del Pan de Azúcar y el Pucará de la Rinconada, que tenían los dueños del ingenio San José (Albeck y Palomeque 2009:203-5).

Al entregar el correspondiente título, el gobernador Mercado de Peñaloza le recordaba al nuevo encomendero Pablo Bernárdez de Ovando, la necesidad de respetar la tierra de sus indios según lo estipulaban las Ordenanzas de Alfaro:

"...dexando a los yndios las tierras que han tenido y poseído y las necesarias para sus chacras y sementeras..." [ y que] conforme a ordenanazas tocan y pertenecen de los Pueblos de Cochinoca y Casabindo..." (AHPS Merced de la Quebrada de las Leñas, 1655: 3) ${ }^{12}$

En este caso parece que el encomendero respetó las tierras indígenas porque no hay quejas ni conflictos al respecto, como sí las habrá sobre la próxima merced de tierras (Albeck y Palomeque 2009). El conflicto por ellas parece desatarse, a medida que las exportaciones de la producción ganadera y otros efectos se fue expandiendo con el desarrollo de algunos mercados mineros y la consolidación de Pablo Bernárdez de Ovando en la encomienda a partir de su participación en las guerras calchaquies. A pesar de las precauciones del gobernador Mercado de Villacorta, el encomendero fue adquiriendo más territorio través de nuevas mercedes, como la de 1662 que abarcaba una parte importante del sector occidental de la Puna (Madrazo1982: 68 y 207, Albeck y Palomeque 2009:203). Esta la estancia de San Joseph, más extensa que la anterior con linderos que iban desde el sur de la laguna de Pozuelos, y traspasando el cerro del Cobre, llegaba más allá del río de las Burras. Su lado oriental coincidía con el límite de la merced de la Quebrada de la Leña y hacia el oeste las altas cumbres de la Cordillera. Las dos mercedes juntas ocupaban toda la parte central de la Puna, y se extendían hacia el sur, hacia la Puna seca. Con estas propiedades los indios de Casabindo y Cochinoca vieron cuestionados sus antiguos derechos de sus tierras. Según Albeck y Palomeque, el encomendero Pablo Bernárdez de Ovando debió haber enfrentado la resistencia indígena frente a esta adjudicación. El accionar indígena parece haber logrado que Bernárdez de Ovando nunca consiguiera plenos derechos sobre estas tierras ya que, hacia el año 1665, existen referencia sobre el "permiso" dado a sus indios para ocupar esas tierras y

12 Agradezco a Fanny Delgado la copia de este documento. 
posteriormente en 1668, hay menciones sobre que los indios de la encomienda pastaban su ganado en la zona (Albeck y Palomeque 2009).

En 1681, el nuevo encomendero Juan José Campero y Herrera decidió cederles el usufructo de las tierras de Cobre y Barranco para que las utilizaran como campos de pastoreo. La donación fue "...por indiviso y por partir con tal que la mitad de dichas tierras las dejen libres para mis ganados y que no las arrienden a persona alguna..." (Citado por Madrazo 1982: 68, también en Albeck y Palomeque 2009: 203). Esta era una de las zonas más áridas de la región y posiblemente la de menor provecho para las producciones del propio encomendero, aunque áridas y elevadas tenían un recurso importante como la sal, que la comunidad había logrado proteger como propiedad de una cofradía (Palomeque 1995).

A fines del siglo XVII, los habitantes del pueblo de Casabindo le señalan al visitador Luján de Vargas que: "... tienen tierras para sembrar...", aunque no lo hacen los de Cochinoca (Boixadós y Zanolli 2003:295). Las tierras agrícolas eran las escasas que tenían al abrigo de las quebradas o quizá en los andenes incas construidos con tal fin (Albeck 1993) y efectivamente, al trasladarlos desde el Pucará hacia el O (a la vera de camino inca), a los indios de Cochinoca los dejaron sin tierras aptas para cultivo. Sobre las tierras de pastoreo de Cobre, en 1710, los señores de Casabindo y Cochinoca lograron un amparo de la real audiencia de Charcas refrendando así sus derechos luego de haber aducido que han estado: "... en pacifica posesión de las tierras de las Barrancas y Cobre (más de 40 años) .... mediante permiso que le dio dicho su encomendero que después se reduxo a donación..." (citado por Albeck y Palomeque 2009: 204). Esta situación ambigua entre el usufructo legalizado por un amparo de la Audiencia y la donación se mantendrá hasta el siglo XIX.

\section{De la frontera incaica a la nueva frontera colonial: los pueblos de indios en el valle de Jujuy. Entre la coacción de los encomenderos y el amparo de las autoridades}

A diferencia de las tierras altas, en las cercanías de la ciudad de Jujuy se levantaron cuatro pueblos de indios pertenecientes a cinco encomiendas. Su población no era originaria del valle, sino que se localizaba en diferentes regiones de los valles orientales cuyo control quedó fuera del espacio colonial durante el siglo XVII ${ }^{13}$. Por las dificultades de accesibilidad de su hábitat, ellos fueron trasladados y asentados en lugares más cercanos a la ciudad de Jujuy. Este grupo de encomiendas había sido entregado a vecinos de la ciudad de Salta tras su fundación entre 1582/4 y se trataba de mercedes

\footnotetext{
13 Sobre las discusiones sobre la localización prehispánica, relaciones con el Tawantinsuyu y pertenencia étnica ver: Salas 1945, Lorandi 1984, Sánchez y Sica1990, Sica 1992, Doucet 1993, Ferreiro1994, Presta 2001, Oliveto y Ventura 2009, Ventura y Oliveto 2014.
}

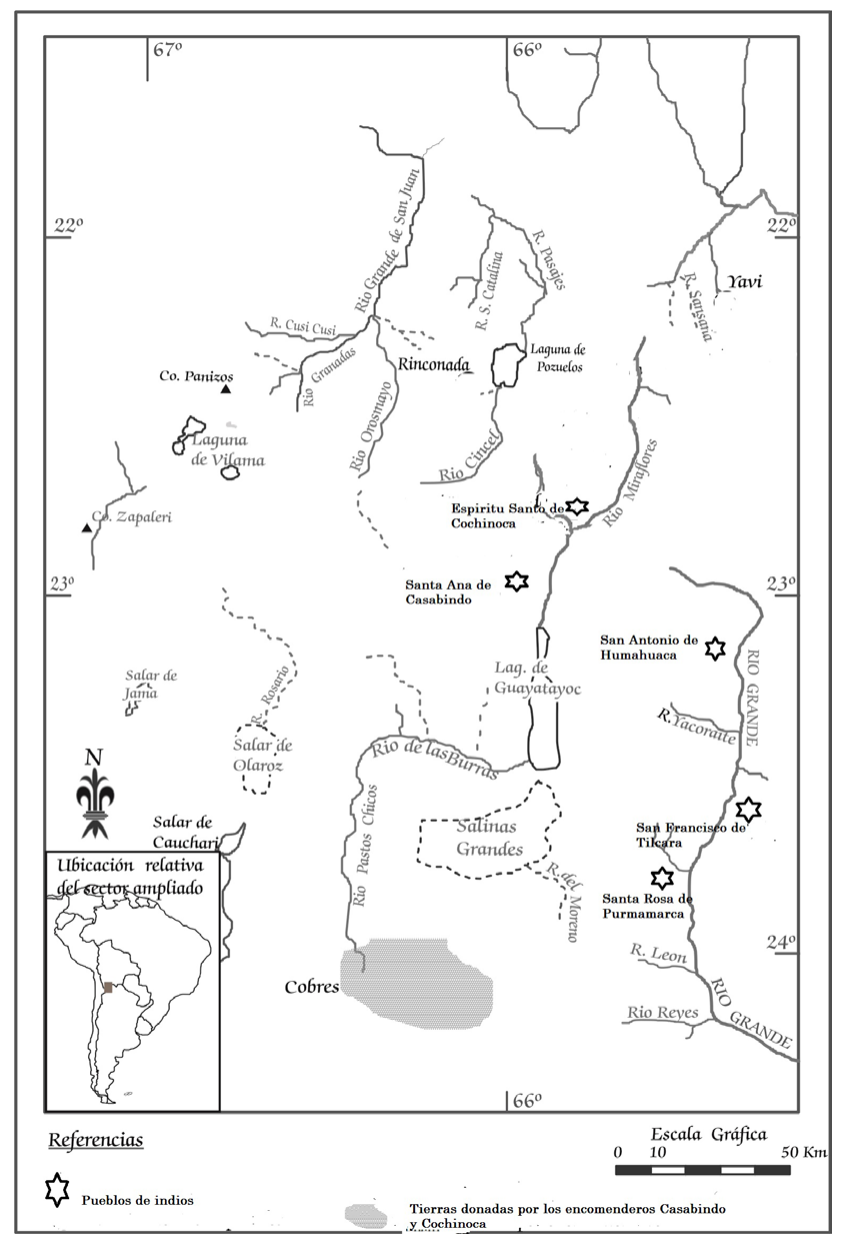

Figura 1: Pueblos de indios tierras altas de Jujuy

Figure 1: Jujuy Highland Indians Peoples

pequeñas con un menor número de tributarios. La fundación de la ciudad de Jujuy, la pacificación de la quebrada de Humahuaca y la intermediación de Viltipoco y los caciques quebradeños le habían permitido la toma de posesión a sus encomenderos, con la presión de las autoridades de Jujuy para que se avecindaran en la nueva ciudad.

En general, y a diferencia de los de la Quebrada y la Puna, en su construcción y constitución eran más precarios que los de las tierras altas. Por su ubicación, en áreas abiertas o pasos de los ríos, quedaron a merced de los ataques de los grupos chaqueños y en la avanzada de la nueva frontera de guerra que se fue consolidando en el siglo XVII. Por esta situación y sumado a la necesidad de mano de obra de los encomenderos tres de ellos sufrieron una serie de traslados a lo largo de este siglo y uno fue reubicado fuera de la jurisdicción de la ciudad de Jujuy.

Ellos fueron los pueblos de San Francisco de Ossas, San Francisco de Paipaya, San Ildefonso de Yala y San Ildefonso de Ocloya. Todos ellos se crearon o reasentaron, en algún momento, en las tierras privadas de sus encomenderos, pero a pesar de ello funcionaron en muchos casos como 
verdaderos pueblos de indios con autoridades, capillas y en algunos casos con cabildos indígenas y cofradías.

Una de las primeras reducciones en el valle de Jujuy fue la de Churumatas en las cercanías del río de Perico. Sin embargo, fue la también la más efímera. Juan Rodríguez de Salazar había obtenido una parte de la encomienda de Churumatas y una estancia en Perico tras la fundación de Salta (Salas 1945; Doucet1993; Cornejo y Vergara 1938). Con la fundación de Jujuy, sus autoridades intentaron negociar el traslado de este grupo a través de la mediación del cacique Viltipoco. Ante la negativa de su principal Laysa y frente al temor que pudieran aliarse con grupos chiriguanos, el gobernador envió a un grupo de vecino dirigidos por Argañaraz a su captura. Tras su derrota, el encomendero Rodríguez de Salazar los asentó en su propiedad de Perico. En un juicio posterior se menciona que la reducción estaba conformada con casas y capilla, y se mantuvo en pie sólo durante siete años. Después, una parte de sus habitantes retornó a los valles Orientales y otra fue trasladada compulsivamente a trabajar en las chacras del encomendero en la jurisdicción de Salta (ATJ legajo 89, 1629:1, Doucet 1993: 77). En la década de 1630, su segundo encomendero decidió instalarse en la Villa de Tarija y se llevó a sus encomendados desde su asentamiento de Salta a dicha ciudad (Doucet 1993: 78-83). En 1645 se encuentran empadronados como habitantes en la villa de Tarija pero pertenecientes a encomenderos del Tucumán (Zanolli 2009, Castro y Palomeque 2016).

Otro de los más antiguos fue el de San Ildefonso de Yala. Levantado a 2 leguas al $\mathrm{N}$ de la ciudad de Jujuy, sobre el camino que iba a la quebrada de Humahuaca. Allí, el encomendero Alonso de Tobar, tras recibir una merced de tierras de parte de Argañaraz, había edificado su casa, hacienda, lagar y el pueblo de sus encomendados recién trasladados posiblemente desde la frontera oriental (ATJ legajo 140, 1640: 2, Sánchez y Sica1990). Este fue el único que no sufrió desplazamientos y que no sufrió ataques de los grupos chaqueños.

Los integrantes de las otras encomiendas, no fueron reducidos hasta después de la llegada del visitador Alfaro, aunque desde 1596 habían sido incluidos en los repartos de la mita de plaza realizados por los gobernadores de Tucumán a instancia del cabildo de Jujuy (Sica 2014b). Su situación fue contemplada por el visitador Alfaro aconsejando a los encomenderos y autoridades:

"...Yten en quanto a los yndios osas y Ocloya y otros semejantes del distrito de jujuy por la gran asperesa de la tierra y dificultad de ser doctrinados asi mesmo se podran ir atrayendo con otros yndios de suerte que con su gusto vengan acercandose donde mas bien puedan ser doctrinados con que no sea a tierras del valle de jujuy ni sus chacaras por ser demaciada calientes sino en tierra puna y del temple de las suyas..." (Levillier 1918: 287)

En el caso de la encomienda de Paipaya, la viuda del primer encomendero dio poder a un vecino de Jujuy para la construcción del pueblo en 1611, seguramente en el contexto de presión que ofrecía la visita de Alfaro. La primera reducción se estableció en una estancia de ganado propiedades del encomendero ubicada en las zonas de yungas, hacia el oriente de Jujuy. Tras varios años en ella, en 1627, el cacique consiguió el apoyo del gobernador de Tucumán Albornoz. Dentro de su política, el gobernador había mostrado una cierta preocupación por la disminución de la población indígena. En esta situación. Albornoz entregó un título al cacique sobre una estancia que pertenecía al encomendero denominada Nacas, cercana a la antigua reducción.

Por poco tiempo pudieron disfrutar de sus tierras, por la necesidad de su encomendero fueron nuevamente trasladados y asentados en la zona sur de la ciudad de Jujuy. Hasta que una nueva coyuntura favorable a los indios se abrió con la visita del gobernador Acosta Padilla a Jujuy en 1648. Durante la misma, pudieron obtener un nuevo título de propiedad sobre otra propiedad de su encomendero ${ }^{14}$. Desgraciadamente, a finales de la década de 1640, la zona donde se ubicaba la chacra del pueblo de San Francisco de Paipaya quedó expuesta a los ataques de los grupos chaqueños que comenzaron a asolar el valle de Jujuy. Los indios se trasladaron a otra tierra más resguardada que pertenecía al patrimonio de su nueva encomendera. A la muerte de la misma, se presentaron a la justicia reclamando la propiedad de la tierra. La justicia dio la razón a los integrantes de la encomienda y la chacra situada en Rio Blanco al S de la ciudad que quedó como propiedad de los integrantes de la encomienda (Sica1992 y 2002).

La gente de la encomienda de Ossas tuvo una historia parecida, ya que su pueblo sufrió diferentes mudanzas forzosas a lo largo del siglo XVII. Ellos formaron parte de la encomienda que Francisco de Argañaraz se concedió

\footnotetext{
${ }^{14}$ El gobernador Acosta y Padilla había manifestado su preocupación por la población indígena del Tucumán y el poder que los encomenderos ejercían sobre ellos. Una de sus cartas al rey sobre la situación en la gobernación, en 1646, tuvo como respuesta una real provisión en que se aconsejaba la necesidad de reducir a la población indígena: "...en mi concexo real de las Indias se a reçebido un papel firmado de don Gutierre de Acosta y Padilla mi gobernador de estas probinçias en que refiere la diminusion ha que an benido los indios de esa probinçia y la despoblasion a que an benido los pueblos della por las opresiones que les açen los encomenderos sirbiendose dellos en diferentes ministerios y ocupandoles en las labores de sus haçiendas y que para remedio desto conbendria reduirlos a tres o quatro poblaçiones para que puedan ser doctrinados y gozar de su libertad sin estar biolentados y oprimidos fuera de su natural..."(citada por González Navarro 2009). En el marco de esta política visitó las encomiendas de Jujuy en 1648, empadronando a la población indígena, obligando a los encomenderos a pagar por el servicio de sus indios y a regularizar situaciones como la del pueblo de Paipaya (Sica 2006, ABNB, Expedientes coloniales 13, 1648).
} 
para sí en 1593. Sin embargo, este encomendero durante su corta vida no reasentó, ni fundó ningún pueblo de indios para esta fracción de su encomienda (si lo hizo para el cuerpo principal de la misma que era Tilcara). Fue su segundo encomendero, Francisco de Argañaraz "el mozo", quien inició la mudanza de esta gente, comenzando un periplo que los llevaría a lo largo de serie de instalaciones provisorias desde los valles Orientales hasta el valle de Jujuy. Cada uno de estos repoblamientos fueron realizados en el lapso que abarcaba desde 1607 a 1624. En ese último año, el encomendero solicitó al cabildo permiso para construir una nueva reducción en una propiedad que tenía en zona al oriente y cercana a Jujuy. En esa ocasión, se le advirtió al cacique que las tierras eran del encomendero y sólo trataba de un asentamiento temporario. El pueblo de San Francisco de Ossas permaneció en esta condición precaria hasta la década de 1660, cuando las expediciones chaqueñas recrudecieron sus ataques a las haciendas y poblados ubicados en las márgenes de la jurisdicción de Jujuy. En ese momento, el pueblo y la estancia de los Ossas -situada en uno de los pasos secundarios hacia la zona del Chacofueron saqueados en varias ocasiones con importante cantidad de pérdidas humanas y materiales ${ }^{15}$.

En ocasión de la visita del gobernador Mercado de Villacorta a Jujuy en el año 1666, la reducción fue trasladado a Rio Blanco a pocas leguas de la ciudad. El grupo aceptó la mudanza con el propósito de obtener la propiedad comunal de las tierras vecinas al nuevo pueblo. Una singular diferencia separaba a este traslado de los anteriores: si en 1624 y durante mucho tiempo el cacique de Ossas y su gente habían aceptado vivir en una propiedad de su encomendero, ahora estaban dispuestos a hacer valer sus derechos y a dotar al nuevo pueblo de tierras de comunidad, tal como estaba previsto en la legislación colonial. Tras nuevos ataques chaqueños que diezmaron la población ${ }^{16}$ y destruyeron la iglesia, el cacique recurrió al arbitrio de las autoridades a fin de cambiar las tierras de su primera reducción (fuera de la línea de ocupación española) por una chacra en Río Blanco que el encomendero había heredado de sus abuelos. Pese a las protestas de su encomendero -Diego Ortiz de Zárate- lograron una merced y la posesión de las chacras de Río Blanco en 1680 (Sánchez 2003; Sica 2006).

El gobernador Mercado de Villacorta también tuvo intervención en la reubicación de la última reducción del pueblo de San Ildefonso de Ocloya en 1666. El mismo había sufrido varios desplazamientos. En los primeros

\footnotetext{
15 "... que actualmente acabada de dar dicho enemigo en el Pueblo de los Ossas distante de esta ciudad tres o quatro leguas y en El muerto y degollado sinco personas y llebadose tres cautibas ...y quemado algunos ranchos del y saqueadolo y hecho pedazo los brasos y piernas de una imagen de Cristo crucificado que estaba en el altar de la yglesia de dicho pueblo..." AHPJ caja XXV, legajo 2, f. 244. También AGI, Charcas 122 citada por Pastell 1912: 356; ATJ legajo 1016, 1726: 20.

${ }^{16}$ Según este documento, por los ataques sólo quedaban unas seis familias de la antigua reducción.
}

tiempos de la encomienda, tras una serie de litigios a finales del siglo XVI, uno de los dos encomenderos no permitió reducir a la población de la encomienda a pesar del compromiso asumido en la carta de concierto que terminó con el juicio y las advertencias del visitador Alfaro sobre la necesidad de crear pueblos de reducción para estas encomiendas ${ }^{17}$.

En la década de 1620, el teniente de gobernador Ledesma Valderrama junto con las autoridades del cabildo jujeño intentaron negociar con los caciques el nuevo sitio de reducción, debido a la necesidad de empadronarlos y de que cumplieran con la mita de plaza que debían a la ciudad de Jujuy. Tras varias reiteraciones de las autoridades del cabildo y el propio gobernador de Tucumán, sumado a una disputa entre jesuitas y franciscanos por la doctrina de Ocloya, se estableció un pueblo en la década de 1640. Pero su ubicación, al oriente de la ciudad de Jujuy y en uno de los pasos principales con la zona chaqueña produjo la necesidad de nuevas mudanzas y la construcción de un fuerte de protección en la zona cuya obra comenzó con la visita del Gobernador Mercado de Villacorta en $1666^{18}$. Tras varias vicisitudes en la que los encomenderos, con la excusa de la peligrosidad, lograron instalar temporariamente a sus encomendados en sus propiedades de Nacas y San Pedrito, a finales de la década de 1680, se fundó la última reducción de San Ildefonso de Ocloya (ubicado al NE y a $40 \mathrm{~km}$ de la ciudad de Jujuy). En este pueblo fueron reunidos los tributarios de las dos encomiendas y se les otorgó la propiedad de extensas tierras comunales que abarcaban gran parte de la cuenca del río Ocloya y con acceso al río San Francisco y las pampas de Ledesma (Tommassini 1933; Sica 2006).

En síntesis, los pueblos asentados en la zona de la antigua frontera oriental del Tawantinsuyu, que se desestructuró apenas ingresaron los españoles al Perú, fueron trasladados hacia el oriente hacia el valle de Jujuy desde la segunda mitad del siglo se transformó en una peligrosa frontera abierta a la invasión y saqueo de los grupos chaqueños.

En 1694, cuando Lujan de Vargas vuelve a la jurisdicción de Jujuy para terminar su visita a las encomiendas de la región, pudo encontrar que la población encomendada se encontraba reunida en diez pueblos de indios y todos ellos tenían tierras ${ }^{19}$. Los de la puna y la quebrada de Humahuaca retrotraían esta posesión a los comienzos del siglo XVII o a la llegada de Alfaro. Los del valle de Jujuy, las habían obtenido en la segunda mitad del siglo

\footnotetext{
${ }_{17}$ Ya que de esta carta de concierto se derivaron la creación de dos encomiendas, más una pequeña fracción de otra parcialidad que había sido otorgadas en Salta (Sica 2006).

18 Hasta esta época, se fueron creando pueblos de reducción en Catalde, Normenta y Caulami (Sica 2006).

19 Los diez pueblos pertenecían a seis encomiendas, ya que la encomienda de Casabindo y Cochinoca tenía dos pueblos de reducción al igual que la de Humahuaca (San Antonio de Humahuaca y San Francisco de Paula de Uquía), mientras que el pueblo de San Idelfonso de Ocloya reunía a la población de dos encomiendas.
} 


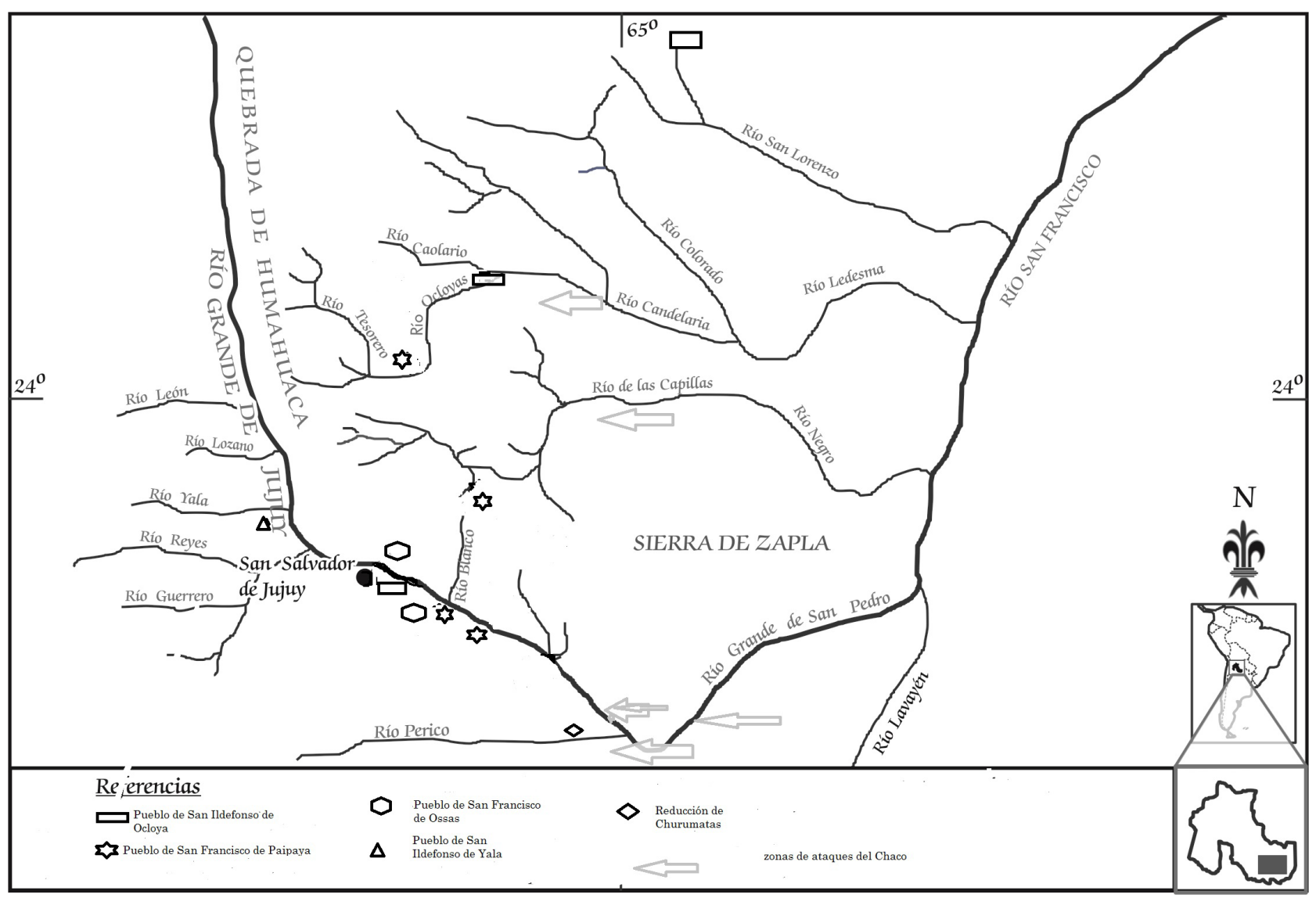

Figura 2: Reducciones del valle de Jujuy

Figure 2: Reductions of the Jujuy Valley

XVII a través de diferentes modalidades: pedidos de amparos, pleitos o por la intervención de las autoridades locales o de la gobernación. En estos casos, los caciques mostraron una importante capacidad para negociar con encomenderos y autoridades, de recurrir a la justicia o aprovechar las coyunturas políticas favorables como las de las gobernaciones o visitas de Felipe de Albornoz, Acosta y Padilla o Mercado de Villacorta.

Este panorama tenía algunas diferencias, contrastaban las extensas posesiones que tenían los pueblos de la quebrada de Humahuaca, que convertían a los indígenas en los mayores propietarios de la región, con las pequeñas chacras de Río Blanco que se habían transformado en las tierras de los pueblos de Ossas y de Paipaya, expuestas a los ataques chaqueños durante gran parte del siglo XVII. Mientras que los de Casabindo y Cochinoca habían visto disminuir sus tierras, primero por la expansión minera y desde la mitad del siglo XVII por los avances de las propiedades de su encomendero. Su resistencia frente a la restricción a su propiedad por la presión de mineros y su encomendero contrastaba con la pacífica posesión de los pueblos de la Quebrada.

La visita de Luján de Vargas no fue significativa para los pueblos de indios de Jujuy. No produjo ninguna sentencia en relación a los pueblos, ya que ellos aparecían como una situación ideal que no necesitaba desagravio, ni modificación, aunque, en algunos casos, como el del pueblo de Yala o las de las de las poblaciones desnaturalizadas del Calchaqui y del $\mathrm{Chaco}^{20}$ distaban del "modelo ideal" que mostraba la visita.

Durante el siglo XVIII, las situaciones que había observado Luján de Vargas se fueron modificando. En la puna, los pueblos de Casabindo y Cochinoca, que continuaron bajo el régimen de encomienda hasta el siglo XIX, habían perdido parte de las tierras entregadas por Alfaro y una

\footnotetext{
20 Esta población fue instalada compulsivamente en Jujuy como consecuencia de los frentes de guerras planteados en los valles Calchaquíes y la frontera del Chaco. Sin embargo, desde la primera mitad del siglo XVII aparecen en las haciendas de Jujuy algunos grupos o personas relocalizadas del valle Calchaquí como producto de las desnaturalizaciones posteriores a las dos grandes rebeliones diaguito- calchaquíes, de 1630-43 y 1659-66. Los traslados forzosos más numerosos se efectuaron después de las campañas militares de 1657 y 1665 . Mercado de Villacorta asentó un grupo de Luracatao en las cercanías de Perico (Sica 2006). La mayor cantidad de cautivos chaqueños se había sumado a la jurisdicción de Jujuy en la década de 1670, consecuencia de dos grandes entradas al Chaco que realizaron conjuntamente las ciudades de Jujuy, Salta, Esteco y Tarija entre 1670 y 71, y la entrada punitiva organizada por el gobernador de Tucumán Ángel Pereda en 1673. En esta última campaña, se encomendaron diferentes grupos a los españoles participantes y se entregaron piezas sueltas bajo la forma de servicio personal. Según A. González Rodríguez más de 318 familias y 22 piezas sueltas se entregaron a vecinos de Jujuy (González Rodríguez 1984:30).
} 
parte de las que le quedaban se encontraban, como dijimos, en una situación ambigua entre el préstamo y la donación.

En la quebrada de Humahuaca, los cuatro pueblos de reducción pertenecientes a tres encomiendas dejaron de estar encomendados y pasaron a tributar a cajas reales después de la década de 1780 (ATJ legajo 1666, 1776, Sánchez 1996: 99, Sica y Ulloa 2016). Las tierras de los pueblos de indios mantuvieron casi los mismos límites establecidos desde el siglo XVII. A diferencia de los Andes centrales, zona en la que el crecimiento demográfico del siglo XVIII generó una presión y un avance de las haciendas sobre las tierras indígenas (Tandeter 1995), en la Quebrada este fenómeno tuvo un alcance más limitado debido al avance del espacio colonial sobre las tierras orientales y el nuevo reparto de mercedes sobre los contrafuertes E y NE de la Quebrada. La expansión territorial alcanzó a los valles orientales colindantes llegando hasta los actuales departamentos de Valle Grande y Ledesma y el de Iruya en Salta. Una parte de estas mercedes fueron

\section{Los pueblos de indios de Jujuy desde el siglo XVIII hasta las primeras décadas del siglo XIX. Entre la estabilidad y la extinción}

concedidas en premio a la participación en las campañas militares al Chaco. Tenían una mayor extensión, que las que se había otorgado en el siglo XVII, ya que su superficie iba desde una y media hasta las seis leguas. Accedieron a ellas, las nuevas familias de la elite de la zona como Portal y de la Tijera, pero también españoles pobres, mestizos, castas o indígenas que actuaron como soldados en la frontera. La posibilidad de obtener nuevas mercedes descomprimió las posibilidades de un avance de las propiedades españolas sobre las tierras indígenas.

En el caso de Tilcara sólo perdió un potrero en la parte alta de la quebrada de Juella y un predio agrícola en el fondo de valle, además de ceder una porción de tierra para el establecimiento de una posta en Hornillo. ${ }^{21}$ Sobre las

tierras de los pueblos de Humahuaca y Uquía sólo hemos encontrado unas pocas menciones de posibles conflictos de linderos con algunas haciendas vecinas,

especialmente las que limitaban con las propiedades de Rodero y de Huacalera, generadas especialmente por su encomendero (AOJ 1775:1; ATJ legajo 956, 1722: 2). Aunque es posible que existieran usurpaciones y pugnas que no llegaron a ventilarse ante las autoridades y la justicia. Tampoco hay registro de pleitos sobre tierras y linderos de Purmamarca.

\footnotetext{
${ }^{21}$ En los últimos años del siglo XVII, el cacique y tributarios del pueblo de Uquía introdujeron ganado en unos potreros de la quebrada de Juella, tierras que pertenecían a Tilcara. El conflicto finalizó en 1699 con la compra de las tierras ocupadas debido a la mediación de las autoridades y el protector de naturales ATJ, 1699, legajo 749, f. 8.
}

Nuevamente los pueblos más afectados serán aquellos provenientes de la frontera oriental, por el desarrollo mercantil en esas tierras y ya no ser necesarios debido al corrimiento de la frontera y al nuevo sistema de defensa en el siglo XVIII. En el caso del Valle de Jujuy, los pueblos de San Francisco de Ossas y San Francisco de Paipaya sólo lograron sobrevivir durante la primera mitad del siglo XVIII. A principios del siglo, las dos encomiendas fueron unidas bajo un mismo encomendero ${ }^{22}$. Por las vicisitudes de su herencia, en la década de 1720, la tutora de la encomendera solicitó una mudanza temporaria de los integrantes del pueblo de Paipaya al pueblo de Río Blanco (reducción de Ossas desde 1680). Ambas reducciones quedaban muy cerca. Fundamentaba este pedido en que la iglesia de Paipaya se encontraba destruida y sus ornamentos e imágenes depositadas en la capilla de Rio Blanco. Esto habilitó a un pedido de merced sobre las tierras del pueblo de Paipaya por parte de un vecino de Jujuy, argumentando que se estaban yermas y sin sembrar desde la mudanza de los indígenas (ATJ legajo $967,1722)$. En 1730, el gobernador amparaba a los indios en su posesión, tras la presentación de los tutores de la encomendera, pero advirtiendo que debían ocuparlas y trabajarlas. La dispersión de la población y la ubicación de las tierras en zonas de importante desarrollo mercantil hicieron difícil el cumplimiento de la sentencia del gobernador, y finalmente las mismas pasaron a manos privadas. San Francisco de Paipaya aparece todavía en la documentación mencionado como pueblo hasta la década de 1730. Al tiempo que las antiguas tierras de la estancia de los Ossas fueron vendidas a terceros tras un complicado litigio entre herederos (ATJ legajo 989, 1724; legajo 990, 1724; legajo 1003,1726)23 En 1773 con la muerte de la última encomendera se extinguen las dos encomiendas de las que sólo quedaban unos pocos tributarios que venían sufriendo una importante dispersión que los encomenderos trataban de cubrir empadronando forasteros o personas pertenecientes a otras $\operatorname{castas}^{24}$. Es posible que, ante el despoblamiento del

\footnotetext{
${ }^{22}$ Pedro Ortiz de Zárate había logrado obtener la posesión de las dos encomiendas por merced del gobernador Zamudio a finales del siglo XVII (ATJ legajo 958, 1723; legajo 1037, 1728).

${ }^{23}$ En la década de 1670, Diego Ortiz de Zárate había logrado obtener el título de la estancia que fue durante casi 40 años la reducción de Ossas. Se la había otorgado en gobernador Ángel Peredo (ATJ legajo 1037,1726). Con la mudanza del pueblo a Río Blanco, la estancia quedó en manos de los herederos de Diego Ortiz de Zárate quienes en la década de 1720 optaron por ponerla en venta para pagar el entierro de la madre de Ortiz de Zárate. Este intento dio lugar a una serie de conflictos entre herederos de las diferentes ramas familiares. En los pleitos se puede ver la rápida valorización de las tierras de la antigua frontera de Jujuy. En un principio la estancia de los Ossas se intentó vender en 1000 y pocos meses su precio se había duplicado (ATJ legajo 990,1724).

${ }^{24}$ En 1722, más de diez tributarios vivían fuera de la reducción conchabado para otras personas. Algunos se encontraban en Salta, Rosario de la Frontera, Tucumán y otras áreas de Jujuy (ATJ legajo 967, 1722). 50 años después ante la escasa población los encomenderos recurrieron a empadronar a personas ajenas a la encomienda: "Asencio, Andres, Gabriel y Manuel Barconti presentan una queja porque Azebey (marido de la encomendera) los hizo empadronar en la encomienda de Paipaya siendo sus abuelos maternos forasteros
} 
pueblo, sus encomenderos decidieran una apropiación de hecho de las tierras y establecer la capellanía sobre las mismas $^{25}$. La maniobra pudo resultar relativamente fácil porque el título original de las tierras de Rio Blanco que los indios habían logrado obtener en 1680- estaban al resguardo de la familia de los encomenderos (ATJ legajo 1037,1735). Cinco años después de la muerte de la encomendera, el antiguo pueblo de Rio Blanco figuraba como una hacienda particular (Rojas1913:180-1).

El pueblo de San Ildefonso de Yala, languidecía dentro de la propiedad privada de antiguos encomendero y nuevos dueños de las tierras. En 1662, los herederos del primer encomendero se vieron obligados a vender la hacienda, que contenía al pueblo, agobiados por las deudas y por el peso de la capellanía establecida por Alonso Tobar a favor del convento de San Francisco. El predio completo fue subastado y adquirido por dos vecinos prominentes de la ciudad (ATJ legajo 1141, 1736). Uno de ellos, Juan Ochoa de Zarate y Ovando intentó obtener en 1670 la investidura de la encomienda cuando esta quedó vacante aunque la perdió ante otro candidato con más poder (Sica 2006). La encomienda pasó a la familia Aguirre Lavayen y la propiedad de la hacienda quedó en manos de Zárate y Ovando, quien la trasmitió por herencia a su familia y a la de la de su hermano en la primera mitad del siglo XVIII. Esta situación no fue aprovechada por los integrantes del pueblo ante Luján de Vargas, ni ante las autoridades para reclamar tierras propias, aunque continuaba habitado por la escasa población de la encomienda, a la que se sumaban forasteros indígenas, mulatos, negros y mestizos (ATJ legajo 943,1721).

En el censo levantado en 1778, el único pueblo de indio registrado en el curato rectoral fue el de San Ildefonso de Ocloya con 39 habitantes, mientras que en las haciendas y propiedades situadas cerca de las antiguas reducciones de Paipaya y Ossas se matriculó una importante cantidad de población indígena, aunque sin consignar su origen (Rojas1913: $)^{26}$. Esto se vuelve a repetir en la revisita de 1786, en la cual sólo se registran dentro del curato rectoral al pueblo de Ocloya y la estancia de Yala, ya que eran las únicas dos encomiendas que existían en esa época en el valle de Jujuy ${ }^{27}$.

El pueblo de San Ildefonso de Ocloya se mantuvo bajo régimen de encomienda hasta comienzos del siglo XIX.

afincados en el pueblo de Humahuaca y su padre también forastero. Un caso similar es el de Asencio Mercado un mulato libre casado con una india huérfana criada por el cacique de Uquía que también fue empadronado compulsivamente en la encomienda de Paipaya (ATJ legajo 1340, 1770).

${ }^{25}$ ATJ legajo 1133, 1773. Agradezco a Mónica Ulloa la copia de este documento.

${ }^{26}$ Por ejemplo, en la hacienda de Palpalá sobre 156 pobladores consignados 132 eran indios, mientras que en la hacienda de Río Blanco se registraron 39 mestizos y 2 indios (Rojas 1913:176-181)

${ }^{27}$ Agradezco a Isabel Castro Olañeta los datos sobre la revisita de 1786 en Jujuy. Sobre la coyuntura y la significación de la misma ver Ferrero 2015.
Durante la segunda mitad del siglo XVIII, las ofensivas sobre la antigua frontera de guerra permitieron la expansión de la frontera agrícola y se valorizaron las tierras que comunicaban la zona de la reducción con las pampas de Ledesma, en donde se comenzaban a desarrollar las primeras haciendas azucareras.

El acceder a tierras era uno de los alicientes principales, para los habitantes de Jujuy, cuando decidían su participación en las campañas punitivas a las tierras bajas de la jurisdicción. A partir de estas expediciones se fueron abriendo nuevos territorios a la ocupación colonial y las mercedes se multiplicaron, generando algunos conflictos de límites entre las tierras comunales del pueblo de Ocloya con las haciendas y estancias vecinas. A finales del siglo XVIII, el capitán del fuerte de Ledesma obtuvo un título de manos del gobernador intendente Mestre sobre una propiedad ubicada en el río de los Catres. La misma limitaba por el S con las tierras comunales de Ocloya. En el acto de posesión, el cacique se opuso a la misma pero no fue escuchado y el acto se concretó abriendo la posibilidad de nuevos litigios (ATJ legajo 1885,1786). Unos años después, el encomendero, el protector de naturales y las autoridades del pueblo intentaron frenar la ocupación de las tierras de Catres aduciendo que las mismas pertenecían a la comunidad y eran arrendadas para sostener los gastos de la capilla del pueblo de Ocloya (ATJ legajo 1956, 1791). En la sucesión de alegatos y contra alegatos, los indígenas no pudieron mostrar los títulos de la merced y pidieron que el deslinde se realizara a vista de ojos y a partir de la memoria oral (ATJ legajo 1999, 1792); logrando obtener el reconocimiento de la justicia sobre su propiedad. Sin embargo, no fue el único conflicto, para ese momento los integrantes del pueblo ya habían obtenido tres amparos del gobernador intendente ante la ocupación con ganado o arrenderos que realizaban los vecinos sobre los linderos de sus extensas tierras comunales. Estos conflictos presagiaban el fin de su propiedad en las próximas décadas.

\section{Epílogo. El fin de las tierras comunales indígenas de Jujuy en el siglo XIX. Entre la propiedad privada y la enfiteusis}

A comienzos del siglo XIX solo pervivían siete de los diez pueblos de indios que Luján de Vargas había empadronado. No todos estaban en la misma situación en relación a sus tierras, ni se enfrentaban a los mismos desafíos. Con la revolución, cesaron las últimas encomiendas y varios de los pueblos, especialmente los del valle de Jujuy se extinguieron definitivamente. Algunos transformándose en poblados rurales como el caso de Yala, o desapareciendo y quedando como propiedades privadas como San Francisco de Ossas y San Francisco de Paipaya.

Los nuevos cambios producidos a partir de 1810 y sobre todo las secuelas que provocaba la militarización 
del territorio y la sociedad jujeña, tuvieron diferentes consecuencias para los pueblos de indios, especialmente para el de Ocloya que era el único que permanecía en pie en el curato rectoral de la ciudad. En 1814, el comandante de Salta, Martín de Güemes, reorganizó la defensa de Jujuy y sus milicias como parte su estrategia militar. Para ampliar el reclutamiento de hombres en la campaña de Jujuy Güemes apeló al apoyo de los antiguos maestres de posta del Camino Real, especialmente los de la Quebrada de Humahuaca, quienes resultaban piezas claves en su táctica de guerra (Paz 2008). Entre ellos, estaba el antiguo maestro de posta de Volcán Bartolomé de la Corte, quién fue designado por el propio Güemes como jefe de las milicias de Jujuy y más adelante teniente gobernador de Jujuy. Su apoyo incondicional, al entonces gobernador a quién también lo unían lazos de parentesco, fue premiado en 1818 con una merced sobre las tierras del pueblo de Ocloya. Los fundamentos de la misma daban cuenta de la reversión al Estado de su propiedad al tratarse de un pueblo de encomienda colonial. De esa manera podía ser asignado nuevamente a un particular, como premio y pago por sus servicios al ejército y a la revolución.

Concluidas las guerras de independencia, tres de los antiguos habitantes del pueblo plantearon la nulidad de la cesión realizada por Güemes. En 1826, se presentaron ante la justicia capitular con el patrocinio del defensor de pobres, invocan su condición de naturales y vecinos del pueblo de Ocloya pero sin hacer alusión a su condición étnica de acuerdo al nuevo contexto político. El pedido fue archivado rápidamente al considerar que las tierras habían pasado al Estado legítimamente y que este hecho había habilitado al gobernador Güemes a entregarlas nuevamente (ATJ legajo 2692,1826). Evidentemente el contexto político comenzaba a ser desfavorable para cualquier reclamo que involucrara las antiguas propiedades comunales ${ }^{28}$.

Veintidós años después, la disputa se reaviva contra esta medida de Güemes y los herederos de Bartolomé de la Corte. En ese momento, los curas rectorales aducirán que las tierras del pueblo de Ocloya pertenecían a la iglesia y como tierras eclesiásticas no debieron quedar bajo la autoridad civil, ni revertir su propiedad al Estado. No eran tiempos propicios para reclamar propiedades eclesiásticas o comunales, en ese momento ya estaban en marcha diferentes proyectos de desamortización. Ante el contexto desfavorable, los curas desistieron de su demanda reconociendo los derechos a la propiedad privada de los herederos de Corte sobre las antiguas tierras comunales de Ocloya (ATJ, legajo 3349, 1848) ${ }^{29}$.

A partir de la revolución y la creación de la provincia de

\footnotetext{
28 Para 1825 ya se había comenzado a debatir en la legislatura de Salta, la continuidad de los cacicazgos y sus formas de elección, medida inicial en la discusión sobre la disolución de las comunidades indígenas (Madrazo 1982: 147).

${ }^{29}$ Agradezco a la Prof. María Eugenia Corte, Directora del Archivo de Tribunales de Jujuy, la orientación para encontrar este documento.
}

Salta (a la que Jujuy estuvo unida hasta 1835), las nuevas autoridades plantearon el debate para promulgar una legislación que suprimiera las comunidades indígenas, los curacazgos y redefinieran los derechos de propiedad de sus tierras. Este proceso no fue lineal, entre 1825 y mediados de la década de 1830 se redactaron y promulgaron nuevas reglamentaciones bajo los principios liberales de la igualdad jurídica y el individualismo, pero los mismos no llegaron a ponerse en práctica. Después de la autonomía de la provincia de Jujuy, en 1835, para los legisladores provinciales la Quebrada de Humahuaca era único lugar del territorio jujeño donde se conservaban tierras comunales y sobre ellas comenzó el proceso de desamortización bajo la figura de la enfiteusis, completada en décadas posteriores por otras leyes como la de venta de tierras públicas ${ }^{30}$. La ley no contempló la situación de la Puna debido a la prolongada situación ambigüedad de las tierras de Casabindo y Cochinoca desde el siglo XVII, que habían sido amparadas en su usufructo, pero no en su propiedad por la Audiencia de Charcas. La misma no fue resuelta durante el siglo XVIII y se fue tornando más precaria con el transcurso del tiempo, hasta que el nuevo contexto político del siglo XIX fue el marco propicio para que las mismas fueron consideradas como propiedad privada de sus antiguos encomenderos (Madrazo1982:147). De las restantes, la dispersión de su población, los avances de las haciendas y propiedades vecinas, la manipulación de sus encomenderos y las propias guerras de la independencia habían dado cuentas de ellas antes de 1839 .

\section{Consideraciones finales}

A finales del siglo XVI, cuando los españoles lograron fundar una ciudad que permitiera el tránsito entre las zonas mineras y la gobernación de Tucumán se abrió una nueva etapa para las antiguas sociedades prehispánicas de la región. La conquista de la jurisdicción de San Salvador de Jujuy permitió que los encomenderos, que provenían de otras ciudades, fueran tomando posesión de sus encomiendas e iniciando el proceso de reasentamiento de la población indígena. El mismo debía estar acompañado por el reconocimiento de tierras comunales tal como establecía la legislación colonial. Sin embargo, para los indígenas encomendados lograr este reconocimiento significó un complejo juego de negoción, resistencia, búsqueda de aliados, uso de la justicia según la presión o coacción que podían ejercer los encomenderos, la historia de cada encomienda, la ubicación de los pueblos y las diferentes coyunturas políticas.

En la adquisición de las tierras de los pueblos de indios de Jujuy podemos encontrar dos momentos diferenciados. En una primera etapa, que iba desde las campañas

\footnotetext{
${ }^{30}$ Los diferentes aspectos tales como: concepción, génesis, aplicación y conflictos de la Ley de enfiteusis y las posteriores han sido tratados en profundidad en los diferentes trabajos de Madrazo 1989, Bushnell 1995, Díaz Rementería 1995, Teruel y Fandos 2009, Fandos y Teruel 2012, Congost 2011, Teruel 2014, Fandos 2014a y 2014 b.
} 
militares sobre el territorio hasta la llegada de Alfaro, los pueblos de las tierras altas obtuvieron o resguardaron una parte de sus antiguos territorios, aunque con algunas diferencias regionales. Los de la quebrada de Humahuaca, protegieron y afirmaron la propiedad antes de la llegada del visitador Alfaro, posiblemente como parte de la negociación de sus caciques con las autoridades tras las campañas militares y a cambio de allanar el acceso a los grupos de la frontera oriental para sus encomenderos, la posibilidad de obtener mayor número de mitayos para la ciudad y consolidar el tránsito por la Quebrada.

Los integrantes de la encomienda de Casabindo y Cochinoca en la Puna, que habían padecido las campañas militares, años antes que la fundación de Jujuy, vieron el avance de la ocupación española sobre sus antiguos debido a la actividad minera que se comenzó a desarrollar en la región. Ambos pueblos habían sido mandados a fundar por un nuevo encomendero, vecino de Salta, a comienzos del siglo XVII. Sin embargo, será el visitador Alfaro quién les señaló tierras en 1612. Desde la segunda mitad del siglo XVII, los pueblos de Casabindo y Cochinoca vieron peligrar nuevamente sus dominios por los avances de la propiedad de su segundo encomendero en su empeño por constituirse en el principal propietario de la región. Sin embargo, los caciques y sus pueblos resistieron a través de la justicia y forzaron al encomendero a permitirles el uso de partes de sus antiguas, que se convirtió luego en una donación del usufructo que fue amparada por la Audiencia de Charcas.

En una segunda etapa, que abarcó la segunda mitad del siglo XVII, los pueblos reducidos en el valle de Jujuy pudieron obtener títulos sobre pequeñas extensiones de tierras que pertenecían a sus encomenderos enmarcado en la acción y medidas de algunos gobernadores en el contexto de las políticas postalfarianas. Tres de ellos, habían sufrido una tortuosa historia de traslados compulsivos y reasentamientos en tierras privadas durante la primera mitad del siglo XVII. En ese período sólo el pueblo de San Francisco de Paipaya había podido acceder a la propiedad de una estancia, que en pocos años se vieron obligados a dejar a sus encomenderos. La situación de asentamiento precario de estos pueblos se agravaba al quedar expuesto a los ataques de grupos chaqueños y en el frente de una frontera de guerra que avanzaba hacía zonas cada vez más cercanas a la ciudad. Sus caciques recurrieron a distintas estrategias como los pedidos de amparo o presentaciones ante la justicia, aprovechando las coyunturas políticas y la acción y medidas de algunos gobernadores como Acosta y Padilla y Mercado de Peñaloza. Sólo el pueblo de San Ildefonso de Yala, un poco más alejado de la línea de frontera no sufrió ningún ataque, aunque su ubicación dentro de la hacienda de su encomendero limitó su crecimiento.

Durante el siglo XVIII, los avances sobre la frontera chaqueña produjeron consecuencias diferenciadas en los pueblos de indios de Jujuy. En el caso de los de la Quebrada, la apertura a la ocupación española de zonas colindante, dando posibilidades de acceder a mercedes de tierras a distintos grupos sociales, descomprimió la extensión de las haciendas y estancias sobre las tierras indígenas, a excepción de unos pocos conflictos puntuales. Para los pueblos del Valle de Jujuy, en su mayoría diezmados por su ubicación en la frontera de guerra, produjo el interés y la revalorización de las tierras en donde sus pueblos y tierras se ubicaban. La fuerte presión por ellas a lo que se sumaba una población diezmada conspiraban contra su conservación. Durante las últimas décadas del siglo XVIII, los encomenderos fueron vendiendo las antiguas reducciones, estableciendo capellanías sobre las propiedades en las que se ubicaba algunos de los pueblos y finalmente en el caso de los pueblos de Yala, Paipaya y Ossas revirtiendo a su patrimonio las antiguas chacras indígenas. Sólo el pueblo de San Ildefonso de Ocloya se mantuvo en pie y en posesión de extensas tierras de comunidad, aunque resistiendo a la intromisión de vecinos y poseedores de nuevas mercedes en una zona que acrecentaba su importancia como paso hacia las nuevas áreas de colonización.

El siglo XIX, la militarización del territorio durante 15 años y los cambios políticos marcaron el final de las propiedades comunales en el territorio jujeño. En las tierras altas de la Puna, las tierras de Casabindo y Cochinoca fueron transformadas en propiedad privada por la familia de sus antiguos encomenderos. Las tierras de Ocloyas se privatizaron de hecho durante el gobierno de Güemes. Quien, en su carácter de gobernador y sin demasiados preámbulos revirtió sus antiguos derechos coloniales al nuevo Estado y las entregó a uno de sus más fieles seguidores. Años después los tímidos intentos por cuestionar esta decisión no encontrarían el contexto propicio para prosperar. Finalmente, las tierras de la quebrada de Humahuaca mantuvieron la propiedad hasta ser objeto de debates y leyes específicas que las declararon extintas como propiedad indígena y la dividieron en nombre de los principios liberales recientemente instaurados.

\section{San Salvador de Jujuy, 15 de octubre de 2106}

\section{Agradecimientos}

Agradezco a Silvia Palomeque por los aportes y comentarios a la primera versión de este trabajo, presentado como ponencia en VI Encuentro de la Red de Estudios Indígenas y Campesinos: "Los pueblos de indios de la Gobernación del Tucumán (siglos XVI-XIX): estado de la cuestión y casos", realizado en la Facultad de Filosofía y Humanidades, Universidad Nacional de Córdoba, con la coordinación de Isabel Castro Olañeta y Sonia Tell a quienes agradezco la invitación a participar del mismo. 


\section{Abreviaturas}

ATJ: Archivo de Tribunales de Jujuy, Argentina AHPJ: Archivo Histórico de la Provincia de Jujuy, Argentina AOJ: Archivo del Obispado de Jujuy, Argentina ABNB: Archivo y Biblioteca Nacional de Bolivia, Sucre, Bolivia

AHPS: Archivo Histórico de la Provincia de Salta, Argentina AGI: Archivo General de Indias, Sevilla, España

\section{Bibliografía}

Albeck, M., Palomeque S. 2009. Ocupación española de las tierras indígenas de la puna y "raya del Tucumán" durante el temprano período colonial. Memoria Americana, $\mathrm{n}^{\circ}$ 17-2: 173-212.

http://www.scielo.org.ar/scielo.php?script=sci_ arttext\&pid=S1851-37512009000200002\&lng=es\&nrm =iso\&tlng=es (Última consulta: 20/10/2016)

Boixadós, R., C. Zanolli (edit.). 2003. La visita de Luján de Vargas a las encomiendas de La Rioja y Jujuy (16693-1694). Estudios preliminares y fuentes. Editorial Universidad Nacional de Quilmes, Buenos Aires.

Castro Olañeta, I. 2006. Pueblos de indios en el espacio del Tucumán colonial. Mata, S, N Areces (coords.). Historia regional. Estudios de casos y reflexiones teóricas, cap. III: 37-49, EDUNSa, Salta.

Castro Olañeta, I. 2015. El oidor de Charcas, Antonio Martinez Lujan de Vargas, y la nueva coyuntura a fines de siglo XVII en el Tucumán. A propósito de los derechos a la tierra de los pueblos de indio". Memoria Americana. Cuadernos de Etnohistoria. 23 (1): 39-67. http://ppct. caicyt.gov.ar/index.php/memoria-americana/article/ view/5888/6185 (Última consulta: 20/10/2016)

Castro Olañeta, I.; Palomeque, S. 2016. Originarios y forasteros del sur andino en el período colonial. América Latina en la Historia Económica, Instituto Mora, México, 23 (3): 37-79.http://alhe.institutomora.edu.mx/index.php/ ALHE/article/view/731 (Última consulta: 20/10/2016)

Congost, R. 2011. De la región de Girona a la Quebrada de Humahuaca. Sobre el modo de afrontar el estudio de las leyes relativas a derechos de propiedad. Wihelmi, M. Bringas, A; Sala I Vila, N. (Ed.). Movimientos indígenas y territorialidad en America Latina: 11-34. Papers de'I IRH, Documenta Universitária, Girona.

Cornejo, A., M. Vergara.1938. Mercedes de tierras y solares (1583-1589). Imprenta San Martín, Salta.

Díaz Rementería, C. J. 1995. Supervivencia y disolución de la comunidad de bienes indígena en la Argentina del siglo XIX. Revista de Historia del Derecho, 30: 11-39, Instituto de investigaciones de Historia del Derecho, Buenos Aires. Doucet, G. 1993. Acerca de los churumatas con especial referencia a los de Tucumán. Revista Histórica $N^{\circ} 17$ : 21-91, PUCP, Lima.

Fandos, C. 2014a. Enfiteutas, propietarios y arrendatarios en el departamento de Humahuaca. Estructura Social y distribución de la riqueza en la década de 1860. Estudios Sociales del NOA, $n^{\circ}$ 3: 41-61, Instituto Interdisciplinario Tilcara, Tilcara- Buenos Aires. http://revistascientificas. filo.uba.ar/index.php/esnoa/article/view/1109 (Última consulta: 20/10/2016)

Fandos, C. 2014b. Tierras comunales indígenas en Argentina. Una relectura de la desarticulación de la propiedad comunal en Jujuy en el siglo XIX. Documentos de Trabajo IELAT: 1 - 31, Instituto de Estudios Latinoamericanos, Universidad de Alcalá de Henares, Madrid. http://dspace.uah.es/dspace/bitstream/ handle/10017/20355/tierras_fandos_IELATDT_2014_ N63. pdf?sequence $=1 \&$ isAllowed $=y$ (Última consulta: 20/10/2016)

Fandos, C., Teruel, A. 2012. “¿Cómo quitarles esas tierras en un día después de 200 años de posesión?" Enfiteusis, legislación y práctica en la Quebrada de Humahuaca (Argentina). Bulletin de I'Institut Français d'Etudes Andines, 41: 209-239, Institut Français d'Etudes Andines, Lima.https://bifea.revues.org/pdf/597 (Última consulta: 20/10/2016)

Ferreiro, J. P. 1994. El Chaco en los Andes. Churumatas, paypayas, yalas y ocloyas en la etnografía del oriente jujeño. Población y sociedad, 2: 3-23, Fundación Yocavil, San Miguel de Tucumán.

Ferrero, P. 2015. "Empadronamientos borbónicos. Contexto de producción y crítica interna de la 'revisita' de pueblos de indios de Córdoba de 1785". Cuadernos de Historia. Serie Economía y Sociedad, 13-14: 81-109. h t t p ://revistas.unc.edu.ar/index.ph p/ cuadernosdehistoriaeys/article/view/11284 (Última consulta: 20/10/2016)

González Navarro, C. 2009. La incorporación de los indios desnaturalizados del valle Calchaquí y de la región del Chaco a la jurisdicción de Córdoba del Tucumán. Una mirada desde la Visita del oidor Antonio Martines Luxan de Vargas (1692-93). Jahrbuch für Geschichte Lateinamerikas , 46: 231-259.http://publicaciones.ffyh. unc.edu.ar/index. php/antropologia/article/view/369 (Última consulta: 22/11/2015).

González Rodríguez, A. 1984. La encomienda en Tucumán. Sevilla, España, Universidad de Sevilla.

Levillier, R. 1918. Correspondencia de la ciudad de Buenos Aires con los reyes de España. Documentos del 
Archivo de Indias. Biblioteca del Congreso de la Nación Argentina: Madrid.

Lizarraga, R. 1928. Descripción colonial. Imprenta Coni, Buenos Aires.

Lorandi, A. 1984. "Pleito de Juan Ochoa de Zárate por la posesión de indios ocloyas. ¿Un caso de verticalidad étnica o un relicto de archipiélago estatal?. Runa, $\mathrm{n}^{\circ} 14$ : 125-45, Facultad de Filosofía y Letras, UBA, Buenos Aires.

Lozano, P. 1943. Descripción corográfica del gran Chaco gualamba. Edición facsimilar, Instituto de Antropología, Universidad Nacional de Tucumán, San Miguel de Tucumán.

Madrazo, G. 1982. Hacienda y encomienda en los Andes. La puna argentina bajo el Marquesado de Tojo. siglos XVII-XIX. Fondo editorial, Buenos Aires.

Madrazo, G. 1990. El proceso enfitéutico y las tierras de indios en la Quebrada de Humahuaca (Pcia. de Jujuy, República Argentina). Período nacional". Andes. Antropología e Historia, 1: 89-114, CEPIHA, UNSa, Salta.

Oliveto, L. G. y Ventura, B. 2009. Dinámicas Poblacionales de los Valles Orientales del sur de Bolivia y norte de Argentina, siglos XV-XVII: Aportes etnohistóricos y arqueológicos. Población y Sociedad, 16, (1): 107119, Fundación Yocavil, San Miguel de Tucumán. http://www.scielo.org.ar/scielo.php?script=sci_arttext \&pid=S1852-85622009000100004 (Última consulta: 20/10/2016)

Palomeque, S. 1995. Intercambios mercantiles y participación indígena en la Puna de Jujuy a fines del período colonial. Revista Andes, 6: 13-49, CEPIHA, UNSa, Salta.

Palomeque, S. 2000. El mundo indígena (siglos XVI-XVIII). Tandeter, E. Nueva Historia Argentina. La sociedad colonial. Cap. 3:87-144, Ed. Sudamericana, Buenos Aires.

Palomeque, S. 2006. Historia de los señores étnicos de Casabindo y Cochinoca. Revista Andes n 17: 139 a 194. http://www.scielo.org.ar/pdf/andes/n17/n17a04.pdf (Última consulta: 20/10/2016)

Palomeque, S. 2010. Los chichas y las visitas toledanas. Las tierras de los chichas de Talina (1573-1595)". Surandino Monográfico, segunda sección del Prohal Monográfico, 1 (2): 1-77.http://www.filo.uba.ar/ contenidos/investigacion/institutos/ravignani/prohal/ SM_002_Articulos/Palomeque.pdf (Última consulta: 20/10/2016)

Palomeque, S. 2015. Crecimiento de la población tributaria originaria de Cochinoca y Casabindo en la segunda mitad del siglo XVII. Revista Estudios del ISHiR,
12 : 9-53. http://revista.ishir-conicet.gov.ar/ojs/index.php/ revistalSHIR (Última consulta: 27/01/2016)

Pastells, P. 1912. Historia de la compañía de Jesús en la provincia del Paraguay, según los documentos originales del Archivo General de Indias. Librería Victoriano Suarez, Madrid.

Paz, G. 2008. "El orden es el desorden". Guerra y movilización campesina en la campaña de Jujuy, 18151821. Fradkin R., J. Gelman (compiladores). Desafíos al orden, política y sociedades rurales durante la Revolución de Independencia. Prohistoria: 83-101, Rosario.

Presta, A. M. 2001. "Hermosos, fértiles y abundantes". Los valles centrales de Tarija y su población en el siglo XVI. Beck, S., Paniagua, N. y Preston, B. (eds.) Historia, ambiente y sociedad en Tarija, Bolivia. 25-39, Universidad Mayor de San Andrés y University of Leeds, La Paz y Leeds.

Rojas, R. 1913. (Recop.). Archivo capitular de Jujuy. Tomo I, Buenos Aires.

Salas, A. 1993. [1945] El antigal de Ciénega Grande (Quebrada de Purmamarca, Provincia de Jujuy). UNJUUBA, Jujuy.

Sánchez, S. 1996. Fragmentos de un tiempo largo. Tilcara entre los siglos XV-XIX. Tesis de Licenciatura en Historia, Facultad de Humanidades y Ciencias Sociales, Universidad Nacional de Jujuy.

Sánchez, S. 2003. Un viaje entre la historia y la memoria: los "ossas" jujeños, Anuario de Estudios Americanos, Tomo LX, I: 41-76.

Sánchez, S., G. Sica.1990. La frontera oriental de Humahuaca y sus con el Chaco. Bulletín del InstituteFrancais d'EtudesAndines, 19(2): 469-497.

Sánchez, S. y Sica, G. 1991. Algunas reflexiones acerca de los tilcaras. Avances en Arqueología n 1: 82-99.

Sica, G. 1992. "Un grupo indígena frente al dominio colonial en Jujuy: el caso de los paipayas. siglo XVII". Facultad de Filosofía y Humanidades, Universidad Nacional de Córdoba, Argentina. Trabajo Final de Licenciatura en Historia. Biblioteca de la Facultad de Filosofía y Humanidades.

Sica, G. 2002. "Vivir en una chacra de españoles": encomienda, tierra y tributo en el pueblo de San Francisco de Paipaya, Jujuy, siglo XVII". Farberman, J., R. Gil Montero. Los pueblos de indios del Tucumán colonial: pervivencia y desestructuración, UNQ/EdiUNJu: 203-226, Buenos Aires.

Sica, G. 2006. "Del Pucara al pueblo de indios. La 
sociedad indígena colonial en Jujuy. siglo XVII". Facultad de Geografía e Historia. Universidad de Sevilla. Departamento de Antropología social. Tesis Doctoral.

Sica, G. 2014a. Paisajes agrarios coloniales en la Quebrada de Humahuaca. Tierras privadas, tierras comunales. siglos XVI-XVIII. Fandos, C. y Teruel, A. Propiedad en la Quebrada de Humahuaca. Historia y actualidad, cap. 1: 17-58, Editorial EDIUNJU, Jujuy.

Sica, G. 2014b. Las otras mitas. Aproximaciones al estudio de la mita de plaza en la jurisdicción de Jujuy, gobernación de Tucumán, siglo XVII. Anuario de Estudios Americanos, vol 71, $n^{\circ}$ 1:201-226.http://estudiosamericanos. revistas.csic.es/index.php/estudiosamericanos/article/ viewArticle/620 (Última consulta: 20/10/2016)

Tandeter, E. 1995. Población y economía en los Andes (siglo XVIII). Revista Andina, 25, año 13, número 1: 7-22.

Tell, S. y Castro Olañeta, I. 2011. El registro y la historia de los pueblos de indios de Córdoba entre los siglos XVI y XIX. Revista del Museo de Antropología, 4 (4): 235-248. http://publicaciones.ffyh.unc.edu.ar/index.php/ antropologia/article/view/369/622 (Última consulta: 20/10/2016)

Teruel, A. 2014. La propiedad territorial en tiempos de la enfiteusis, Fandos C., A. Teruel (comp.) Quebrada de Humahuaca. Estudios históricos y antropológicos en torno a las formas de propiedad, cap. 2: 59-94, EDIUNJu,
San Salvador de Jujuy.

Teruel, A. y Fandos, C. 2009. Procesos de privatización y desarticulación de tierras en el norte argentino a fines del siglo XIX. Revista Complutense de Historia de América, 35: 233-255.http://revistas.ucm.es/index.php/ RCHA/article/view/RCHA0909110233A (Última consulta: 20/10/2016)

Tommasini, G. 1990 [1933] Los indios Ocloya y sus doctrineros en el siglo XVII. Universidad Nacional de Jujuy, San Salvador de Jujuy, Argentina.

Ventura, B. y Oliveto, G. 2014. Resabios de otros tiempos. Dominio incaico en los valles orientales del norte de Salta, Argentina. Bulletin del IFEA; 43 (2): 285-310.https://bifea. revues.org/5248 (Última consulta: 20/10/2016)

Vergara, M.1996. Orígenes de Jujuy, Gobierno de la Provincia de Jujuy, San Salvador de Jujuy.

Zanolli, C.2005. Tierra, encomienda e identidad: Humahuaca (1540-1638). Sociedad Argentina de Antropología, Buenos Aires.

Zanolli, C. 2008. Dos visitas coloniales a la jurisdicción de San Bernardo de la frontera de Tarija, 1645 y 1659, UBA. FFyL, Buenos Aires. 